\title{
CRISE DENTRO DA CRISE: A INSERÇÃO LABORAL JUVENIL E SUA CONFIGURAÇÃO NO CONTEXTO DO NOVO CORONAVÍRUS
}

\author{
CRISIS WITHIN THE CRISIS: THE YOUTH LABORAL INSERTION AND ITS \\ CONFIGURATION IN THE NEW CORONAVIRUS CONTEXT
}

\section{CRISIS DENTRO DE LA CRISIS: LA INSERCIÓN LABORAL JUVENIL Y SU CONFIGURACIÓN EN EL CONTEXTO DEL NUEVO CORONAVIRUS}

\section{Resumo}

Gustavo Bruno Pereira de Souza 1 Maria das Dores Saraiva de Loreto ${ }^{2}$ Lilian Perdigão Caixêta Reis ${ }^{3}$

A recente pandemia causada pelo novo coronavírus desencadeou um cenário de elevada incerteza e seus impactos certamente tendem a ser sentidos no mercado de trabalho. A partir de uma investigação bibliográfica, buscou-se realizar uma discussão e reflexão sobre como as desigualdades de inserção laboral juvenil, bem como as desigualdades sociais, já existentes na sociedade brasileira, foram significativamente ampliadas em decorrência das medidas de contenção e transmissibilidade da propagação do vírus. Os resultados sugerem que as ações de combate e retardamento da COVID-19, aliadas ao cenário político e econômico nacional, considerado ainda mais incerto nesse momento atual, contribuíram para o aprofundamento da crise econômica e social, tornando determinados grupos sociais ainda mais vulneráveis, como é o caso dos jovens, em termos de precarização ou perda do trabalho, redução dos rendimentos, problemas relacionais e psicológicos.

Palavras-chave: COVID-19. Crise Econômica. Juventude. Inserção Laboral.

\begin{abstract}
The recent pandemic caused by the new coronavirus has triggered a scenario of high uncertainty and its impacts certainly tend to be felt in the job market. From a bibliographic review, we sought to conduct a discussion and reflection on how the inequalities of youth work insertion, as well as the social inequalities, already existing in Brazilian society, were significantly expanded as a result of the measures containment and transmissibility of the spread of the virus. The results suggest that the combat and retardation actions of COVID-19, combined with the national political and economic scenario, considered even more uncertain at this current moment, contributed to the deepening of the economic and social crisis, making certain social groups even more vulnerable, such is the case of young people, in terms of job insecurity or loss, reduced income, relational and psychological problems.
\end{abstract}

Keywords: COVID-19. Economic Crisis. Youth. Employment Insertion.

\begin{abstract}
Resumen
La reciente pandemia provocada por el nuevo coronavirus ha desencadenado un escenario de alta incertidumbre y sus impactos ciertamente tienden a sentirse en el mercado laboral. A partir de una investigación bibliográfica, se buscó realizar una discusión y reflexión sobre cómo las desigualdades de inserción laboral juvenil, así como las desigualdades sociales, ya existentes en la sociedad brasileña, se ampliaron significativamente como resultado de las medidas. contención y transmisibilidad de la propagación del virus. Los resultados sugieren que las acciones de combate y retardo del COVID-19, sumadas al escenario político y económico nacional, considerado aún más incierto en el momento actual, contribuyeron a la profundización de la crisis económica y social, haciendo aún más vulnerables a ciertos grupos sociales, como es el caso de los jóvenes, en términos de inseguridad laboral o pérdida, ingresos reducidos, problemas relacionales y psicológicos.
\end{abstract}

Palabras clave: COVID-19. Crisis económica. Juventud. Inserción laboral.

\footnotetext{
1 Bacharel em Administração. Mestrando no Programa de Pós-Graduação em Economia Doméstica da Universidade Federal de Viçosa. E-mail: qustavobsouza@ufv.br. ORCID: https://orcid.org/0000-0002-1383-4624

2 Pós-doutorado em Família e Meio Ambiente pela University of Guelph - Canadá. Professora do Programa de Pós-Graduação em Economia Doméstica da Universidade Federal de Viçosa. E-mail: mdora@ufv.br. ORCID: https://orcid.org/0000-0001-7418-2669

3 P'ós-doutorado pela Universidade Federal da Bahia. Doutorado em Psicologia pela mesma instituição. Professora do programa de Pós-Graduação em Economia Doméstica da Universidade Federal de Viçosa. E-mail: lilian.perdigao@ufv.br. ORCID: http://orcid.org/0000-0001-6827-871X
} 


\section{INTRODUÇÃO}

O ambiente do trabalho vive, na atualidade, os efeitos de uma crise com novas particularidades. Para além do problema sanitário, os efeitos nefastos dessa nova doença desencadeada por um novo tipo de coronavírus (COVID-19), levam a graves efeitos econômicos e sociais e, certamente, com impactos negativos sobre um dos fatores essenciais do sistema econômico, o mercado de trabalho (BORSATTO et al., 2020, MAGALHÃES; CARDOSO, 2020, COSTA, 2020). Suas repercussões, habitualmente negativas, estão ocorrendo e sendo sentidas nos mais diversos setores da economia, dado ao chamado "isolamento social", ativado pela ampla maioria dos governos, interno e externos, para tentar minimizar a contaminação (PEDROSO; CORCIOLI; FOGUESATTO, 2020).

Cronologicamente, quando se debruça sobre o caso nacional, uma questão que parece importante para propiciar melhor embasamento do problema norteador desse trabalho, como reportado por Araújo et al., (2010) e Dedecca (2015), são as profundas transformações ocorridas na economia brasileira a partir da década de 1990, momento, no qual, observou-se a condução de muitas políticas macroeconômicas voltadas, principalmente, para a estabilização de preços, período que remonta, inclusive, a criação do Plano Real em 1994, estratégias adotadas, ao que parece, para melhor inserção do país na nova ordem econômica internacional (ARAÚJO et al., 2010, DEDECCA, 2015).

Apesar da reformulação do papel do Estado e da reestruturação produtiva, observada principalmente nos anos iniciais do século XXI, sendo uma das principais características que marcam esse período a estabilidade política e econômica, parece existir um movimento na literatura (JINKINGS, 2003, POCHMANN, 2004, FRIGOTTO, 2004, RAITZ; PETTERS, 2008, ROCHA, 2008, ARAÚJO et. al., 2010, DEDECCA, 2015, OLIVEIRA; BATISTA, 2017, D'AGOSTINI; TITTON, 2019, CORSEUIL; POLOPONSKY; FRANCA, 2020, KWADO, 2020, KURNAZ, 2020) que evidencia que o crescimento econômico brasileiro produziu nítido efeito favorável na redução da pobreza absoluta, mas incerto e não previsível efeito sobre a distribuição da renda, sendo que, a população jovem se configura num público mais vulnerável frente às situações de vulnerabilidade social, como o desemprego, por exemplo.

Esse público, de maneira geral, mesmo quando se analisa vários recortes socioeconômicos - nível de escolaridade, gênero, faixa etária - parece encontrar maiores dificuldades de inserção no mercado de trabalho, como aponta Corseuil, Poloponsky e Franca (2020), e, muitas vezes, ocupam as vagas de trabalho mais precárias, dado que os jovens 
tendem a sofrer mais com crises econômicas e com outras dificuldades, considerando que têm de competir, no mercado de trabalho, com indivíduos com maior experiência (ROCHA, 2008, CORSEUIL; POLOPONSKY; FRANCA, 2020, KURNAZ, 2020).

A juventude, portanto, já enfrentava grandes desafios. A taxa média de desemprego, de acordo com dados da PNAD Contínua divulgados no segundo trimestre de 2020 pelo IBGE, entre a população de 18 a 24 anos de idade era de $30 \%$, o que significa mais que o dobro da taxa média de desemprego da população em geral, 13,3\%. Além disso, considerando os anos mais recentes (2015-2020), observa-se um acentuado agravamento do cenário econômico e político nacional, no qual, no período pré-pandemia, já eram consistentes o número de pessoas desempregas no país, flutuando em torno de 12 milhões, de acordo com dados do IBGE (2020).

Paralelamente, em decorrência das ações implementadas no combate a pandemia fechamento de fronteiras e encerramento de atividades não essenciais - houve uma diminuição na oferta e na demanda agregada (SILVA, 2020). Este ambiente adverso, ocasionado por esse período pandêmico, contribuiu para a ampliação expressiva e acelerada da percepção de incerteza empresarial no âmbito da economia brasileira gerando falências, redução das compras por parte das famílias, postergação da decisão de produção e investimento das empresas, aumento do desemprego formal e informal, como reportado por Silva (2020), Campelo Júnior e Bittencourt (2020) e em estudos e pesquisas realizados pelo Instituto Brasileiro de Geografia e Estatística (2020), em levantamentos feitos por meio da PNAD COVID-19.

De fato, parece ser correto dizer que a crise econômica desencadeada pela COVID-19 se somou a uma outra crise, de proporções muito grandes, que já havia na economia brasileira, advinda da ideologia neoliberal reestabelecida nos anos finais da segunda década do século XXI, que está agravando desigualdades históricas que já existiam, refletindo expressivamente especificidades da sociedade capitalista, que foram historicamente construídas no Brasil, no qual a inclusão produtiva precarizada jovializou-se novamente, atingindo com mais força e rapidez os jovens, em detrimento aos outros grupos populacionais (FRIGOTTO, 2004, POCHMANN, 2004, LEITE, 2020).

Diante do exposto, o objetivo desse trabalho, de cunho bibliográfico, consiste em refletir sobre o cenário do mercado de trabalho para o segmento juvenil, considerando, sobretudo, esse contexto de pandemia, marcado por baixo crescimento econômico e por altas taxas de desemprego. Dessa forma, a questiona-se: De que forma a pandemia da COVID-19 ressalta a 
desigualdade brasileira e ameaça os empregos? Como a crise provocada pelo novo coronavírus impacta a juventude brasileira?

Para a consecução do objetivo proposto, primeiramente, foi apresentada uma breve discussão acerca de alguns elementos referentes a pandemia e seu impacto na economia e no agravamento de desigualdades sociais. Discutiu-se, ainda, acerca da relação dos jovens e do mercado de trabalho na perspectiva de alguns estudiosos da área, bem como de que forma as mudanças observadas mais recentemente, ocasionadas pelo coronavírus, estão transformando o mundo do trabalho.

\section{PROCEDIMENTOS METODOLOGICOS}

Visando alcançar uma compreensão mais profunda do problema delineado, enquanto abordagem para coleta de dados, optou-se pela pesquisa bibliográfica. A pesquisa bibliográfica sustenta qualquer investigação científica, sendo condição essencial para avançar em praticamente todos os campos do conhecimento. Essa técnica, que é desenvolvida com base em material já elaborado, envolve consulta e localização de fontes escritas, constituídas fundamentalmente de livros e artigos científicos. Gil (2002) ainda salienta que os preceitos dessa técnica abrangem o investigador com a bibliografia já tornada pública em relação ao tema de estudo, munindo-o, dessa forma, com boa parte da contribuição científica realizada sobre determinado temática (GIL, 2002, MARCONI; LAKATOS, 2003).

Portanto, dado o objetivo proposto, esta é mais útil, uma vez que permitir ao investigador agrupar uma ampla gama de informações, mais ampla do que aquela que poderia ser pesquisada de forma diretamente, vantagem particularmente importante quando o problema de pesquisa requer dados muito dispersos, como é o caso deste artigo, assegurando-se, todavia, das condições em que esses dados foram obtidos, que posteriormente foram analisados em profundidade de forma cuidadosa (GIL, 2002).

Outro critério determinante para a escolha dessa técnica, como ressaltado por Gil (2002), está no fato desta possibilitar a rápida obtenção das informações requeridas, propiciando, dessa forma, maior conhecimento, visando responder com mais exatidão e detalhes as questões que envolvem o problema norteador desse trabalho.

A busca por artigos foi realizada principalmente em bases de dados indexadas pela Web of Science, a fim de obter dados de periódicos com melhores avaliações. A análise dos dados foi orientada pela técnica de Análise de Conteúdo, baseando-se nos preceitos e técnicas metodológicas desenvolvidos por Bardin (2011). A escolha se deveu ao fato deste método ser 
mais adequado para o aprofundamento investigativo e análise das informações, que possibilitam melhor compreensão do contexto e, consequentemente, permitem a realização da discussão sobre o tema.

\section{A CRISE PANDÊMICA E SEUS IMPACTOS ECONÔMICOS E SOCIAIS: BREVES CONSIDERAÇÕES}

Magalhães e Cardoso (2020) ressaltam que diferentemente de outras crises econômicas, que foram focalizadas, sobretudo, em setores financeiros e bancários - como a Grande Depressão, por exemplo - a atual crise, considerando o cenário nacional, atinge fortemente o setor de serviços e a indústria. Conjuntamente, esses dois setores, de acordo com os supracitados autores, são responsáveis por aproximadamente $80 \%$ do Produto Interno Bruto - PIB (soma das riquezas produzidas por um país em determinado período de tempo). Ou seja, é uma crise econômica de grande magnitude.

O cenário econômico brasileiro antes do surto de coronavírus, comparado com o período de 2001 a 2010, no qual o Brasil cresceu em média 3,7\% ao ano, já apresentava uma lenta recuperação econômica, dado que, na década atual, de 2011 a 2019, a média anual de crescimento do PIB foi de apenas $0,6 \%$ ao ano (BARBOSA FILHO, 2017, MAGALHÃES; CARDOSO, 2020).

Dentro dessa mesma perspectiva de tentar analisar o cenário econômico e político brasileiro antes do surto de coronavírus, Barbosa Filho (2017) também ressalta que a desaceleração da economia brasileira que teve início, segundo a autor, no ano de 2014, período marcado por grande descontrole das contas públicas, acentuada elevação do risco país, baixo crescimento, cenário fiscal que tendia a alto endividamento, redução gradual do ritmo de crescimento, dentre outros, são fatores estruturais que ajudam a explicar o fraco dinamismo econômico brasileiro atual: baixa produtividade, baixa qualidade educacional, pequeno investimento em ciência, sistema tributário distorcido, instituições fracas e insegurança jurídica (DEDECCA, 2015, BARBOSA FILHO, 2017, MAGALHÃES; CARDOSO, 2020).

Tendo já sido feita uma exposição breve do cenário econômico e político no qual a pandemia atingiu o Brasil, apresenta-se os dados do estudo "Impacto Fiscal da Pandemia: Andando sobre Gelo Fino", de autoria de Marcos Lisboa, Marcelo Gazzano, Marcos Mendes e Vinícius Botelho, no qual estima-se que a despesa extraordinária com a pandemia de coronavírus possa superar $\mathrm{R} \$ 900$ bilhões, fazendo com que o déficit nas contas públicas 
segue a $R \$ 1,2$ trilhão em 2020 , cerca de dez vezes o projetado no início do ano, segundo Lisboa et al., (2020).

Além disso, os quatro pesquisadores traçaram diversos cenários para a dívida bruta. Evidenciou-se, a partir dos dados apresentados, que mesmo no cenário mais otimista que prevê que o PIB brasileiro recue 5\% em 2020 e cresça, na média, 3\% ao ano a partir de 2021, com os juros reais da dívida caindo para $2 \%$ ao ano, a dívida pública só cairia para menos de 100\% do PIB por volta de 2030 (LISBOA et al., 2020).

Ademais, como a situação fiscal brasileira - que possui endividamento público de aproximadamente $73,4 \%$ em relação ao PIB, em média, países emergentes possuem endividamento de aproximadamente 47,7\% - como reportado por Magalhães e Cardoso (2020) a partir de dados divulgados pelo Banco Mundial, referentes, segundo os autores, ao último ano disponível (2016), o aumento do déficit público em decorrência da pandemia, gera o risco de insustentabilidade da dívida pública.

Considerando ainda o atual cenário político, no qual parece permanecer, pelo menos no que diz respeito a pandemia, uma ausência de estratégias integradas e uma falta de direcionamento claro para o efetivo combate da COVID-19, pode haver o risco de que a elevação contínua da dívida pública, aliado ao aumento das incertezas ameace os investimentos e torne-se um empecilho ao crescimento (MAGALHÃES; CARDOSO, 2020).

Outro fator importante para explicar as nuances entre economia e pandemia é o isolamento social. Essa estratégia, adotada na ampla maioria dos países, indicada, inclusive, pela Organização Mundial de Saúde (OMS), como meio de inibir a transmissibilidade da doença, provocou o fechamento de unidades de produção, logística, comércio varejista, choques na oferta e demanda de produtos e serviços e afetou também a regularidade do funcionamento de cadeias de insumos, como reportado por Silva (2020) e Pathak, Gope e Bader (2020).

Com certeza, o Brasil não é imune a esse ambiente, o qual contribuiu para a percepção de incerteza empresarial no âmbito da economia brasileira, como demonstrado no gráfico 1 (que pode ser visualizado abaixo), que demonstra o Indicador de Incerteza da Economia Brasil (IEE-Br), elaborado por Campelo Júnior e Bittencourt (2020, p. 11), divulgado recentemente pelo "Boletim Macro" calculado pelo Instituto Brasileiro de Economia (IBRE) da Fundação Getúlio Vargas (FGV). 
Gráfico 1 - Indicador de Incerteza da Economia Brasil (IEE-Br) - em pontos

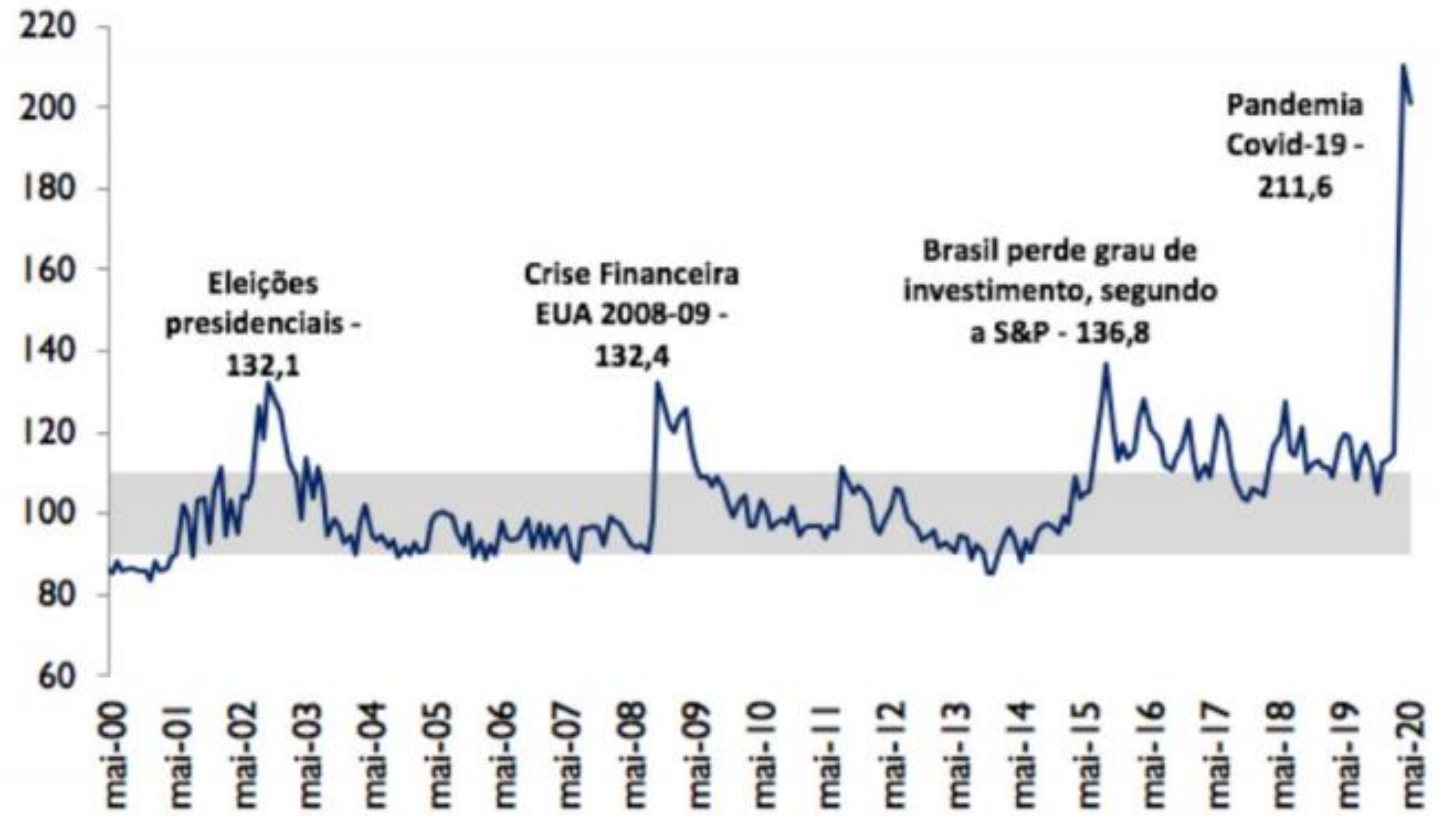

Fonte: Campelo Júnior e Bittencourt (2020, p. 11).

Os dados publicados e ressaltados por esse índice citado acima, reafirmam que com o aprofundamento da crise sanitária e econômica, o índice de desconfiança aumentou alcançando níveis históricos. Os resultados sugerem também certa incerteza que turva e compromete a confiança no sentido macro, ativam, além disso, comportamentos prudenciais nos agentes econômicos e, consequentemente, retardam decisões de consumo das famílias e investimentos das empresas (SILVA, 2020, CAMPELO JÚNIOR; BITTENCOURT, 2020, MAGALHÃES; CARDOSO, 2020).

De forma complementar, Leite (2020, p. 11) lembra ainda que:

O Brasil é caracterizado, historicamente, por profundas desigualdades sociais e econômicas e por uma estruturação precária do mercado de trabalho que aprofunda desigualdades e concentra renda, situação ainda mais agravada com a (contra)reforma trabalhista de 2017 e (contra)reforma da Previdência em 2019.

Dados apresentados por Magalhães e Cardoso (2020), sistematizados a partir de projeções da Economist Intelligence Unit - EIU, endossam essa perspectiva levantada por Leite (2020), ao advertirem para a possibilidade do Brasil sofrer efeitos econômicos mais severos do que a média mundial, com a renda do brasileiro caindo em relação ao resto do mundo.

De acordo com Leite (2020), embora o vírus da SARS-CoV-2, tenha capacidade de atingir todos indistintamente, ele não produz as mesmas consequências quando atinge sociedades mais desiguais, como o Brasil, pois, como destacam Batista et al., (2020) ocorre 
um avanço maior de mortes entre a população pobre e negra, o que é um indicativo de desigualdades estruturais da sociedade brasileira.

Como demonstrado por Batista et al., (2020), a progressão dos casos confirmados da COVID-19 no Brasil parece que tem sido influenciada também por fatores socioeconômicos, além da própria dinâmica de contágio. Ou seja, quando se analisa o número de óbitos pelo nível de escolaridade do paciente (gráfico 2), observa-se que as pessoas com nível de escolaridade superior apresentaram uma menor proporção de óbitos (22,54\%), que aquelas sem escolaridade (71,31\%). Constatou-se, portanto, que quanto maior o nível de escolaridade, menor a letalidade. Deduz-se, então que esse efeito pode ser resultado de diferenças de renda, que geram disparidades no acesso aos serviços básicos sanitários e de saúde (BATISTA et al., 2020).

Gráfico 2 - Proporção de óbitos ou recuperados por nível de Escolaridade do paciente

Fonte: Batista et al., (2020).
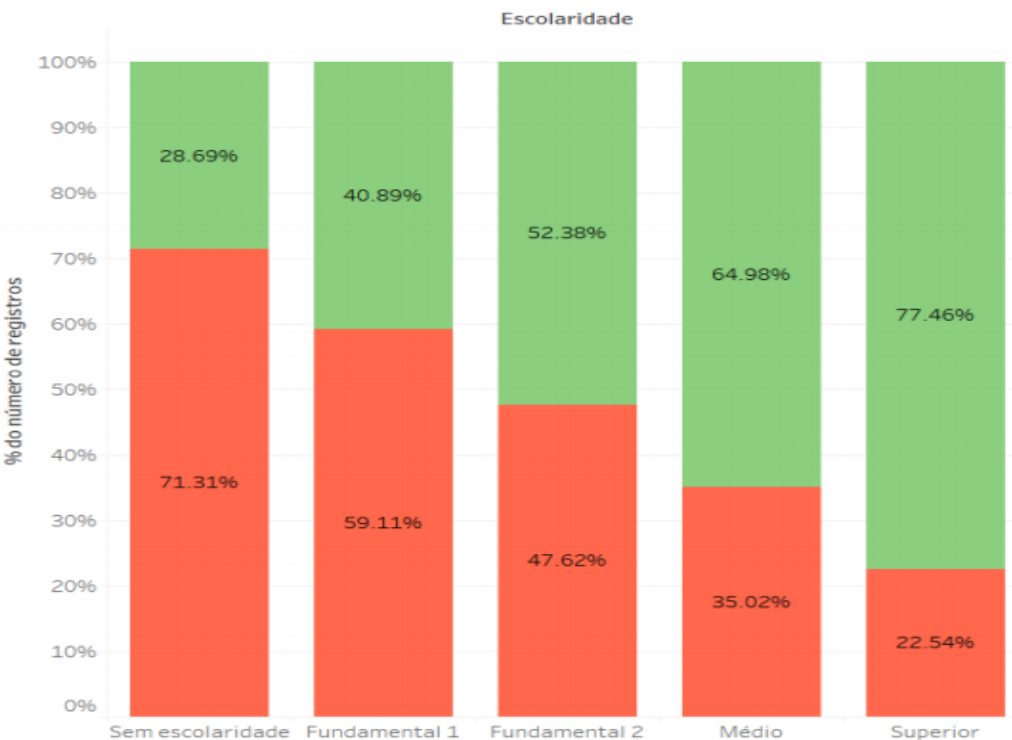

No gráfico 3 (abaixo), cujos dados ainda dizem respeito ao trabalho de Batista et al., (2020), é apresentado os dados da proporção de óbitos e recuperados em relação ao nível de escolaridade combinado com a raça/cor. Observa-se, também, que pretos e pardos apresentaram maior percentagem de óbitos em relação aos brancos, em todos os níveis de escolaridade. Além disso, pretos e pardos apresentaram proporção de óbitos, em média, 37\% maior do que brancos na mesma faixa de escolaridade, com a maior diferença sendo no nível superior (50\%) (BATISTA et al., 2020). 
Gráfico 3 - Proporção de óbitos ou recuperados por escolaridade e Raça/Cor
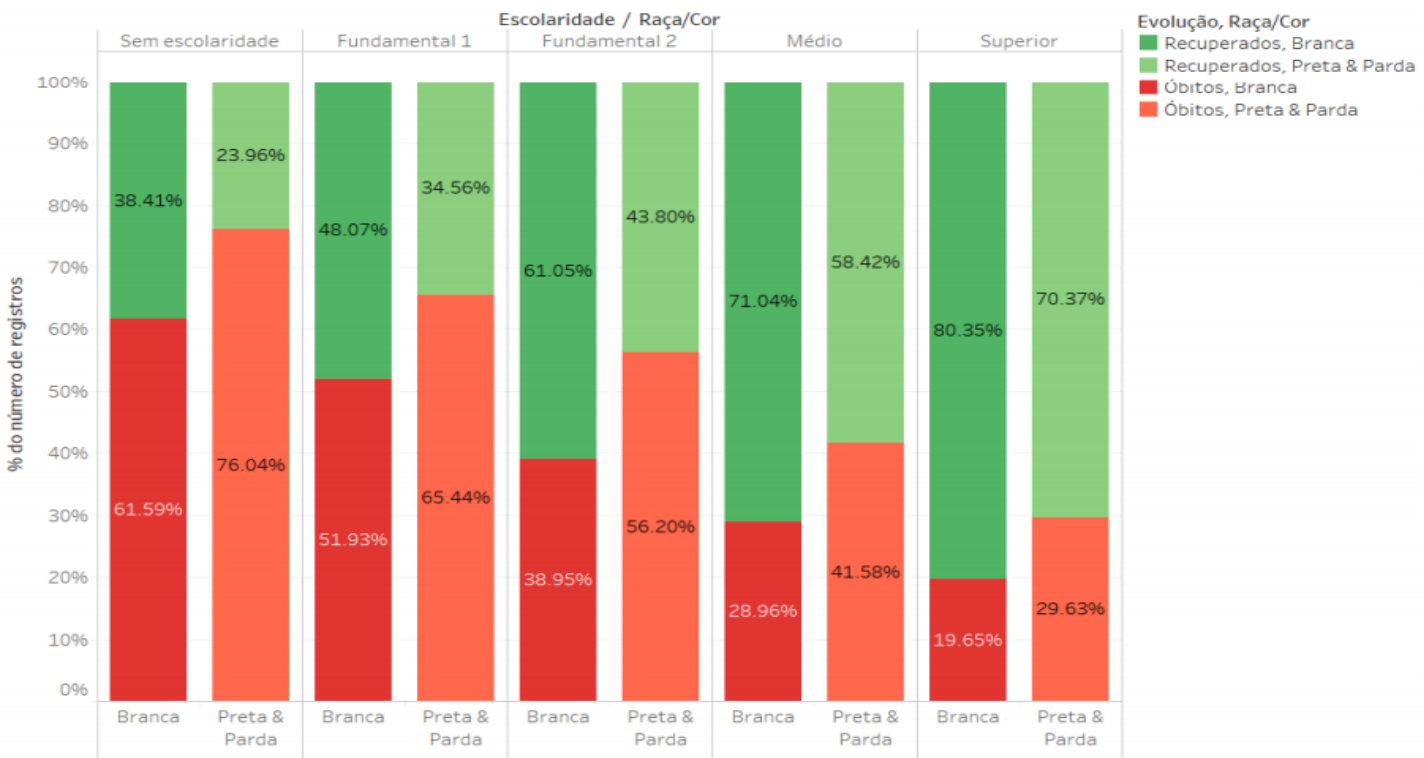

Fonte: Batista et al., (2020).

Essa perspectiva de desigualdades é endossada por Furceri et al., (2020), ao analisarem dados das cinco grandes epidemias deste século - SARS (2003), H1N1 (2009), MERS (2012), EBOLA (2014) e ZIKA (2016) - constataram que elas levam a um aumento persistente e significativo do Coeficiente de Gini (mede o grau de desigualdade de um dado país). Nos países afetados, como constatado pelos autores, o coeficiente aumentou 1,25 pontos percentuais após cinco anos do início de cada epidemia.

Um outro canal relacionado que as epidemias podem afetar a desigualdade, de acordo com Furceri et al., (2020), é por meio de impactos nas perspectivas de emprego para alguns grupos de trabalhadores, especialmente aqueles com baixa qualificação.

Infere-se, portanto, que particularmente no Brasil, o impacto da COVID-19 não é o mesmo para todos, os efeitos refletem desigualdades e desequilíbrios já existentes no interior da nossa sociedade. Além do impacto no mercado de trabalho e seus efeitos no aprofundamento da desigualdade social, como ressaltado acima, outros recortes, como o acesso à educação e a segurança alimentar por exemplo, também sublinham essas desigualdades em tempos de pandemia, como reportado por Magalhães e Cardoso (2020), Leite (2020), Amorim, Júnior Ribeiro e Bandoni (2020), Owusu-fordjour, Koomson e Hanson (2020), Pathak, Gope e Bader (2020), Pedroso, Corcioli e Foguesatto (2020), Reis et al., (2020) e Sambuichi et al., (2020). 


\section{JUVENTUDE E INSERÇÃO PRODUTIVA: NUANCES E PERSPECTIVAS}

Esse tópico centrou-se em identificar estudos que apresentaram elementos sobre a inserção dos jovens no mercado de trabalho, bem como que investigaram, a partir da problematização proposta juntamente com o arcabouço teórico, fatores que são relevantes para explicar as nuances entre a juventude e o desemprego e que, além disso, podem propiciar melhor entendimento da origem e da ontologia dessa questão, com vistas à melhor compreender seus desdobramentos e suas perspectivas.

Na pesquisa bibliográfica tem-se o trabalho de Jinkings (2003), Oliveira e Batista (2017) e Leite (2020). Nos estudos supracitados, os autores indicam que a partir da década de 1970, criaram-se condições, políticas e econômicas, para que o modelo de produção neoliberal desabrochasse, quando a economia mundial apresentou claros sinais de estagnação, com altos índices inflacionários. Os preceitos Tayloristas e Fordistas, que, até então, vigoravam no mundo do trabalho, como modelo de organização da produção a ser seguido, declinaram-se, principalmente, por volta das décadas de 1940 e 1950, por decorrência do movimento instaurado no pós-guerra, baseado no novo sistema de organização do trabalho e das relações produtivas (JINKINGS, 2003).

De forma complementar, Oliveira e Batista (2017) ressaltaram que, com essa reestruturação produtiva, os grandes conglomerados industriais e empresariais, que adquiriram papel preponderante na nova ordem mundial recém estabelecida, para acompanhar 0 dinamismo na produção e se tornarem competitivas, passaram a exigir pessoas detentoras de características de polivalência. Os supracitados autores afirmaram que em decorrência desse aumento na competitividade dos mercados, bem como, das mudanças nas tecnologias em espaços temporais cada vez menores, aliado à forte propagação do discurso neoliberal contra o Estado intervencionista, ocorreram fortes efeitos no contexto macroeconômico, afetando a vida de muitas pessoas, que foram cada vez mais atingidas na forma de socialização, nos seus modos de vida e na relação estabelecida com o trabalho.

Ou seja, as mudanças estruturais que ocorreram nos sistemas produtivos para fazer face à globalização, assim como a consequente busca por competitividade pelos agentes econômicos é o que parece ter levado a esse processo de modificação expressiva nos modelos produtivos e nas condições de reprodução da força de trabalho (JINKINGS, 2003, RAITZ; PETTERS, 2008).

Nesse sentido Leite (2020, p. 4) ressaltou que: 
[...] cabe destacar que para o adequado enquadramento do neoliberalismo faz-se necessário ter presente que ele faz parte de um complexo processo de reestruturação capitalista da sociedade, que produz continuamente uma precarização do trabalho e da vida que possui como ponto de inflexão a crise dos anos de 1970, configurando-se como uma crise do modo de regulação fordista/ keynesianista que, depois de atingir seu ápice, apresenta seus próprios limites e contradições internas abrindo um amplo processo de contra-reformas, dentre as quais a neoliberal [...]

A respeito desta realidade, é nesse sentido que D’agostini e Titton (2019) relacionaram a precarização do trabalho com a juventude. Ou seja, em função dessas profundas alterações ocorridas no ambiente macroeconômico, o qual agravou a situação de vulnerabilidade econômica em que vive um grande número de famílias, sensivelmente intensificada por essa crise conjuntural e estrutural, a literatura recorrentemente aponta que o desequilíbrio no mercado de trabalho (apesar de atingir todos os trabalhadores, tanto os não qualificados como aqueles altamente qualificados, nos países periféricos bem como nos desenvolvidos) tem os jovens como o grupo social cuja respectiva taxa de desemprego possui maior sensibilidade a esse cenário, uma vez que, normalmente, esse público já está em situação de desvantagem por ter menos acúmulo de capital humano e menos proteção contra demissões (ROCHA, 2008, OLIVEIRA; BATISTA, 2017, D’AGOSTINI; TITTON, 2019, KWADO, 2020, KURNAZ, 2020, CORSEUIL; POLOPONSKY; FRANCA, 2020).

Leite (2020, p. 8) também endossa essa perspectiva, ao afirmar que:

O resultado, portanto, das políticas de austeridade recaíram sobre os(as) trabalhadores(as) na forma de reformas trabalhistas e previdenciárias, na elevação das taxas de desemprego, no subemprego, na informalidade, na precarização, no aumento das desigualdades, da pobreza, da polarização social e política diante dos ajustes que excluem cidadãos do acesso a serviços e direitos [...]

Infere-se dizer, portanto, que tais transformações no mercado de trabalho configuram-se em impasses aos jovens, principalmente os de baixa renda. Outro fato a ser considerado, como assevera Jinkings (2003), é que essas novas formas produtivas adquirem configurações distintas nos diversos setores produtivos e nos diferentes países, conforme seus níveis de desenvolvimento econômico (ROCHA, 2008).

No caso brasileiro, embora seja reconhecido como país em desenvolvimento, em reconhecimento aos avanços nos indicadores sociais e econômicos, das últimas décadas, que podem ser observados, quando se analisa a tendência de diminuição do Coeficiente de Gini, principalmente ao longo da primeira década de 2000, ainda é possível observar muitos contrastes entre a riqueza e a pobreza existentes no país: baixa qualidade habitacional, carências generalizadas em infraestrutura, serviços deficientes, dentre outros. 
Até mesmo a rápida recuperação da economia brasileira, expressa em taxas de crescimento nos anos de 2003 a 2010, mesmo diante do cenário de crise internacional, não se manteve (BARBOSA FILHO, 2017). O resultado observado nos últimos anos não confirmou o prognóstico de crescimento e a estimativa, inicialmente de expansão, veio perdendo força com as dificuldades encontradas para ampliar o crescimento econômico que, inclusive, tenderam a turvar a expectativa quanto à capacidade de o país dar continuidade ao movimento de redução da desigualdade de renda e estabelecer igual tendência para os demais indicadores de desigualdade de natureza socioeconômica (DEDECCA, 2015).

Então, considera-se expressivas algumas imposições que reforçam os efeitos dessa precarização sobre o segmento juvenil, especialmente na realidade brasileira, no qual, as pessoas entre 15 e 29 anos, configuram-se como contingente expressivo da população, próximo de 52 milhões de pessoas em 2017 (estimativas do IBGE). Sendo que, contingentes expressivos da população jovem trabalha e 52,6\% da população de 25 anos ou mais não completaram a educação escolar básica e obrigatória, em 2018; ou seja, não concluíram no mínimo o ensino médio (PNAD CONTíNUA, 2019b).

A Organização Mundial do Trabalho (OIT) sublinha que o desemprego juvenil no Brasil chegou ao maior índice em quase três décadas em 2017, no qual 30\% dos jovens entre 15 e 24 anos buscavam uma ocupação (OIT, 2017). O Instituto Brasileiro de Geografia e Estatística (2019), também apresenta dados preocupantes em relação ao desemprego da população para essa faixa etária. Segundo o relatório "Síntese de Indicadores Sociais: Uma Análise das Condições de Vida da População Brasileira" (IBGE, 2019), o grupo etário mais afetado pela desocupação é o das pessoas entre 14 a 29 anos. Para esse grupo, a taxa de desocupação, que era de 13,0\% em 2014, aumentou ano após ano, até alcançar 22,6\% em 2017, mantendose em 22,3\% em 2018. Infere-se, portanto, que conjunturas econômicas desfavoráveis tendem a atingir com mais intensidade a ocupação dos jovens, que levam maior tempo para se recuperar posteriormente.

De acordo com Corseuil, Poloponsky e Franca (2020), a conjuntura do mercado de trabalho nos anos mais recentes tem também destacado um expressivo aumento na taxa do desemprego jovem. Dados apresentados pelos autores demonstram que o aumento do desemprego ocorreu de forma generalizada entre todos os recortes socioeconômicos, como demonstra a tabela 1.

Tabela 1 - Taxa de desemprego dos jovens de 15 a 29 anos, por características socioeconômicas (em porcentagem). 


\begin{tabular}{|c|c|c|c|c|c|c|}
\hline Ano & $1^{2}$ trim. 2013 & 12 trim. 2015 & 12 trim. 2017 & $1^{2}$ trim. 2019 & $\begin{array}{l}\text { Variação (10 trim. } \\
2017-1^{12} \text { trim. } \\
2015)\end{array}$ & $\begin{array}{c}\text { Variação (10 trim. } \\
2019 \text { - 1a trim. } \\
2013)\end{array}$ \\
\hline Jovens & 14,5 & 15,1 & 24,9 & 23,9 & 9,8 & 9,4 \\
\hline \multicolumn{7}{|l|}{ Faixa etária } \\
\hline 15 a 17 anos & 25,2 & 26,6 & 45,8 & 45,4 & 19,2 & 20,2 \\
\hline 18 a 24 anos & 16,4 & 17,6 & 28,7 & 27,3 & 11,1 & 10,8 \\
\hline 25 a 29 anos & 9,5 & 9,6 & 15,7 & 15,3 & 6,1 & 5,8 \\
\hline \multicolumn{7}{|l|}{ Gênero } \\
\hline Homens & 11,9 & 12,6 & 21,9 & 20,9 & 9,3 & 9,0 \\
\hline Mulheres & 17,8 & 18,3 & 28,8 & 27,5 & 10,4 & 9,7 \\
\hline \multicolumn{7}{|l|}{ Nivel de ensino } \\
\hline Fundamental incompleto & 15,0 & 15,3 & 26,6 & 25,1 & 11,2 & 10,0 \\
\hline Fundamental completo & 14,4 & 15,1 & 24,7 & 23,7 & 9,6 & 9,3 \\
\hline
\end{tabular}

Fonte: Elaborado por Corseuil, Poloponsky e Franca (2020, p. 13), a partir de dados da PNAD Contínua/IBGE.

É possível observar a partir dos dados apresentados pelos autores que o primeiro trimestre de 2017 registrou o maior valor da taxa em todas as desagregações. $\mathrm{Na}$ desagregação por faixa etária, o grupo dos adolescentes (15-17 anos) foi o mais afetado, com um crescimento de 20 pontos percentuais entre os primeiros trimestres de 2013 e 2019, passando de 25,2\%, no primeiro trimestre de 2013, para 45,4\%, no mesmo trimestre de 2019. Entre os jovens de 18 a 24 anos, o aumento do desemprego em todo o período analisado foi de 10,8 pontos percentuais, chegando a 27,3\% em 2019 (CORSEUIL; POLOPONSKY; FRANCA, 2020).

Os supracitados autores destacam, além disso, que quando se analisa o recorte por gênero, entre os primeiros trimestres de 2013 e 2019, as taxas de desemprego de homens e de mulheres registraram aumentos de 9,0 e 9,7 pontos percentuais, respectivamente. $\mathrm{Na}$ desagregação por nível de educação, segundo os autores, os menos escolarizados (fundamental incompleto) registraram um crescimento de 11,2 pontos percentuais na taxa de desemprego entre o terceiro trimestre de 2013 e o mesmo trimestre de 2017, quando essa taxa passou de $15,0 \%$ para $26,6 \%$. Os jovens com fundamental completo tiveram um crescimento de 9,6 pontos percentuais no mesmo período (CORSEUIL; POLOPONSKY; FRANCA, 2020).

Corseuil, Poloponsky e Franca (2020) parecem afirmar que o cenário no mercado de trabalho, na segunda metade da última década do século $\mathrm{XXI}$, foi afetado por uma escassez de oportunidades de trabalho para esse segmento juvenil. 
Em suma, constatou-se a partir da pesquisa bibliográfica que, a situação em que se encontra a economia brasileira, desde de meados de 2014, cria um ambiente de forte recessão que reduz a capacidade de crescimento do país.

Além disso, debruçando-se sobre a situação dos jovens, no que diz respeito à inserção produtiva, considerando a realidade brasileira, infere-se que, esse público, sobretudo aos pertencentes as classes populares, tende a sofrer um processo de adultização mais precoce, com tendência de ingressar muito cedo no mercado de trabalho, geralmente, com baixa escolarização, quase sempre ocupando as vagas de menor remuneração disponíveis, dada a pouca experiência e acúmulo de capital humano, conjugadas com posições nas bases operacionais da hierarquia do trabalho (JINKINGS, 2003, POCHMANN, 2004, FRIGOTTO, 2004, RAITZ; PETTERS, 2008, ROCHA, 2008, OLIVEIRA; BATISTA, 2017, D'AGOSTINI; TITTON, 2019, CORSEUIL; POLOPONSKY; FRANCA, 2020, KWADO, 2020, KURNAZ, 2020).

De forma complementar Pochmann (2004) considera que os filhos dos mais pobres tendem a encontrar no trabalho uma das poucas condições de mobilidade social. Uma situação, portanto, muito diversa da dos jovens de "classe média/média alta", que, geralmente, estendem a infância e a juventude. Fato que contribui para que esses trabalhadores não tenham acesso às já escassas oportunidades dignas de inserção laboral.

Portanto, considerando que, em situações aparentemente normais, os jovens, sobretudo, configuram-se como público mais vulnerável frente a situações de desemprego, aliado ao fato de que a perda acumulada do Produto Interno Bruto (PIB) do Brasil nos últimos anos, é uma das maiores desde de 1980 (COMITÊ DE DATAÇÃO DO CICLO ECONÔMICO DA FUNDAÇÃO GETÚLIO VARGAS - CODACE, 2017), a nova crise desencadeada pelo novo coronavírus, pareceu se tornar elemento ampliador deteriorante para aqueles que já são diretamente afetados por cenários adversos.

Dados da Organização Internacional do Trabalho (OIT, 2020), evidenciaram que, entre os menores de 29 anos, um em cada seis jovens parou de trabalhar desde o surgimento da COVID-19; ou seja, 267 milhões de jovens estão desempregados, sem frequentar escolas nem cursos profissionalizantes. Cabe aqui um destaque para os dados do relatório "Juventude e pandemia no Brasil" que destacam que a maior preocupação dos 33 mil jovens que participaram da maior pesquisa feita no Brasil sobre essa temática, realizada pelo Conselho Nacional da Juventude (Conjuve), a qual contou com a participação de outras organizações, relevam que o âmbito econômico, especificamente, causa muita preocupação para os jovens, sendo que, mais da metade deles já relatou sofrer mudanças em sua carga horária de trabalho. 
O impacto nas atividades geradoras de renda é especialmente severo para os trabalhadores desprotegidos e para os grupos mais vulneráveis e que estão na economia informal, situação vivenciada por muitos jovens brasileiros. Tomasi e Corrochano (2020), também ressaltaram que muitos programas e políticas que ganharam muita visibilidade, como o Programa Nacional de Inclusão do Jovem, por exemplo, criado em 2005 por demandas da sociedade e pela construção da cidadania no âmbito democrático, passou por várias reveses e reformulações até que, em 2008, recebeu nova denominação "Programa Integrado da Juventude", incorporando diferentes programas até então existentes, em decorrência da frágil articulação com outras políticas educacionais e com o sistema público de trabalho, emprego e renda.

Deste modo, como ressalta Leite (2020), a já precária estruturação do mercado de trabalho brasileiro e os ataques que a legislação trabalhista vem sofrendo nos últimos anos compõem o cenário no qual se insere a pandemia que prejudica, sobretudo, aos trabalhadores informais, já precarizados, como os jovens, por exemplo.

\section{CONSIDERAÇÕES FINAIS}

De fato, a crise provocada pela pandemia, com repercussões sanitárias, econômicas e sociais, revelou as muitas fragilidades da economia brasileira, que se baseia, se constrói e se apoia no trabalho informal e na produção de bens primários para exportação, principalmente. Nesse contexto de profundas transformações políticas, econômicas e sociais, o debate sobre a juventude tem se tornado cada vez mais importante e recorrente, em reconhecimento as dificuldades enfrentadas por esse grupo na sua transição para o mundo do trabalho.

Nesse cenário pandêmico evidenciou-se, também, a naturalização de desigualdades estruturais da nossa sociedade, com impactos sobre aqueles grupos mais vulneráveis, como é o caso da juventude, não somente por sua menor competitividade e experiência, mas também pela lenta recuperação econômica, dadas as repercussões sobre o desemprego e de uma maior precarização do trabalho, condições acentuadas na pandemia, que refletem não somente em termos da perda de rendimentos ou poder de consumo, mas que podem também ocasionar problemas psicológicos e societais.

Por fim, vale destacar que o trabalho não teve como objetivo responder e esclarecer todas as dúvidas e questões que perpassam o tema. Contudo, acredita-se que a produção de novo conhecimento, mesmo sendo desafiador produzir algo com conteúdo inédito ou inovador, possa fortalecer o campo da literatura nessa área, seja apontando grandes tendências, 
auxiliando práticos e/ou podendo levantar desvelamentos que poderão ser melhor investigados futuramente, dando publicidade a questão, tão importante e que afeta a vida de muitas pessoas. É o que se procura resgatar com esse trabalho, como subsídio para o debate.

Quando se investiga tais questões, mesmo com limitações metodológicas, infere-se que os jovens se encontram inseridos em ocupações cada vez mais precárias, sem ou pouco apoio legal, com mudanças em sua carga horária de trabalho, bem como em situação de desemprego, vivendo à margem da sociedade, muitas vezes, sem acesso a direitos básicos.

\section{REFERÊNCIAS BIBLIOGRÁFICAS}

AMORIM, Ana Laura Benevenuto; JÚNIOR RIBEIRO, José Raimundo; BANDONI, Daniel Henrique. Programa Nacional de Alimentação Escolar: Estratégias para enfrentar a insegurança alimentar durante e após a COVID-19. Revista de Administração Pública, Rio de Janeiro, v. 54, n. 4, p. 1134-1145, 2020.

ARAÚJO, Eliane Cristina de. et al. A condição do jovem no mercado de trabalho brasileiro: Uma análise comparativa entre o emprego e o primeiro emprego (1999-2009). Economia e Tecnologia, ano 06, vol. 23, p. 29-39, 2010.

BARDIN, Laurence. Análise de Conteúdo. Editora Almedina. São Paulo, 2011.

BATISTA, Amanda. et al. Análise socioeconômica da taxa de letalidade da COVID-19 no Brasil. Núcleo de Operações e Inteligência em Saúde (NOIS), Rio de Janeiro, Nota Técnica nº 11, mai. 2020.

BARBOSA FILHO, Fernando de Holanda. A crise econômica de 2014/2017. Estudos Avançados, v.31, n. 89, p. 51-60, 2017.

BORSATTO, Ricardo Serra. et al. Respostas dos Municípios para garantir Segurança Alimentar e nutricional em tempo de pandemia. preprints.scielo.org Disponível em: https://preprints.scielo.org/index.php/scielo/preprint/download/163/222/211 . Acesso em: 02 set. 2020.

CAMPELO JÚNIOR, Aloísio; BITTENCOURT, Viviane Seda. Expectativas de empresários e consumidores: acomodação da confiança em níveis muito baixos. Boletim Macro FGV/IBRE, maio de 2020. Disponível em: https://portalibre.fgv.br/sites/default/files/202005/boletimmacroibre 2005.pdf. Acesso em: 12 out. 2020 ás 16:29.

CORSEUIL, Carlos Henrique Leite; POLOPONSKY, Katcha; FRANCA, Maria Penna. Diagnóstico da inserção dos jovens brasileiros no mercado de trabalho em um contexto de crise e maior flexibilização. Brasília, Instituto de Pesquisa Econômica Aplicada, Brasília, 2020. Disponível em: https://www.ipea.gov.br/portal/images/stories/PDFs/relatorio institucional/200707 ri diagnostic o de insercao de jovens.pdf 
COMITÊ DE DATAÇÃO DO CICLO ECONÔMICO DA FUNDAÇÃO GETÚLIO VARGAS (CODACE). Rio de Janeiro, 2017. Disponível em: https://portalibre.fgv.br/sites/default/files/2020-03/comite-de-data o-de-ciclos-econ micoscomunicado-de-30 10 2017- 1 .pdf. Acesso em: 31 ago 2020 ás 11:08.

COSTA, Simone da Silva. Pandemia e Desemprego no Brasil. Revista de Administração Pública, v.54, n. 4, p. 969-978, 2020.

DEDECCA, Claudio Salvadori. A redução da Desigualdade e seus desafios, Brasília, p. 469512, 2015. In: CALIXTRE, André Bojikian; BIANCARELLI, André Martins; CINTRA, Marcos Antônio Macedo (Organizadores). Presente e Futuro do Desenvolvimento Brasileiro. Brasília, IPEA, 2015.

D'AGOSTINI, Adriana; TITTON, Mauro. Youth in the context of chronic unemployment in Spain and Brazil. International Journal of Lifelong Education. v. 18, n.3, p. 18-30, 2019.

FRIGOTTO, Gaudêncio. Juventude, Trabalho e Educação no Brasil: Perplexidades, desafios e perspectivas. In: NOVAES, Regina; VANNUCHI, Paulo (Organizadores). Juventude e Sociedade: Trabalho, Educação, Cultura e Participação. São Paulo, Editora Fundação Perseu Abramo, p. 180-216, 2004.

FURCERI, Davide. et al. COVID-19 will raise inequality if past pandemics are a guide. Vox CEPR Policy Portal, 2020. Disponível em: https://voxeu.org/article/covid-19-will-raise-inequalityif-pastpandemics-are-guide . Acesso em: 12 out. 2020.

GIL, Antônio Carlos. Como Elaborar Projetos de Pesquisa. Editora Atlas: São Paulo, 2002.

INSTITUTO BRASILEIRO DE GEOGRAFIA E ESTATÍSTICA. Síntese de Indicadores Sociais: Uma Análise das Condições de Vida da População Brasileira (2019). Disponível em: https://biblioteca.ibge.gov.br/visualizacao/livros/liv101678.pdf. Acesso em 12 out. 2020.

INSTITUTO BRASILEIRO DE GEOGRAFIA E ESTATÍSTICA. Pesquisa Nacional por Amostra de Domicílios Contínua Segundo Trimestre de 2020. Disponível em: https://biblioteca.ibge.gov.br/visualizacao/periodicos/2421/pnact 2020 2tri.pdf. Acesso em: 12 out. 2020a.

INSTITUTO BRASILEIRO DE GEOGRAFIA E ESTATÍSTICA. Pesquisa Nacional por Amostra de Domicílios Contínua Módulo Educação (2019). Disponível em: https://biblioteca.ibge.gov.br/visualizacao/livros/liv101657 informativo.pdf . Acesso em: 18 out. 2020b.

JINKINGS, Isabela. Reestruturação produtiva e mercado de trabalho na indústria têxtil catarinense. Revista de Ciências Humanas EDUFSC, Florianópolis, n. 33, p. 71-94, 2003. Disponível em: https://periodicos.ufsc.br/index.php/revistacfh/article/download/25366/22293. Acesso em: 14 out. 2020.

KURNAZ BALTACI, Işıll. Youth Unemployment and Challenging Labor Market Conditions Reaching to the Future: The Case of Diyarbakır, Sur Region. Amme Idaresi Dergisi. v. 53 Issue 1, p119-152, Mar 2020. 
KWAIDO, Amina Ahmad. Impact of entrepreneurship education on youth unemployment: a case of ummaru ali shinkafi polytechnic sokoto, nigeria. Proceedings of Economics and Finance Conferences. International Institute of Social and Economic Sciences, 2020.

LEITE, Kelen Christina. A (in)esperada pandemia e suas implicações para o mundo do trabalho. Psicologia \& Sociedade, 32, e020009. DOI: http://dx.doi.org/10.1590/1807$\underline{0310 / 2020 v 32240215}$

LISBOA, Marcos. et al. Impacto Fiscal da Pandemia: Andando sobre gelo fino. Disponível em: https://www.joserobertoafonso.com.br/impacto-fiscal-da-pandemialisboa-et-al/ . Acesso em: 12 out. 2020.

MAGALHÃES, Graziella; CARDOSO, Leonardo Chaves Borges. Efeitos econômicos e distributivos da pandemia de coronavírus no Brasil. Revista de Economia e Agronegócio. $v$. 18, n. 1, p. 1-12, 2020.

MARCONI, Maria de Andrada; LAKATOS, Eva Maria. Fundamentos de Metodologia

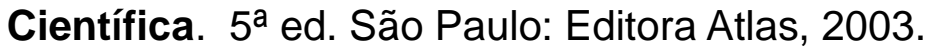

ORGANIZAÇÃO INTERNACIONAL DO TRABALHO (OIT). Global Employment Trends for Youth 2017: Paths to a better working future. Disponível em: https://www.ilo.org/global/lang-en/index.htm .OIT, 2017a.

ORGANIZAÇÃO INTERNACIONAL DO TRABALHO (OIT). ILO Monitor: COVID-19 and the world of work. Fourth edition: Updated estimates and analysis. Organização Internacional do Trabalho, 2020b. Disponível em: https://www.ilo.org/wcmsp5/groups/public/---dgreports/--dcomm/documents/briefingnote/wcms 745963.pdf. OIT, 2020b.

OLIVEIRA, Salvador Domingues; BATISTA, Sueli Soares dos Santos. Empregabilidade e inserção social dos jovens como desafios para a educação profissional e tecnológica. Impulso, v.27, n. 70, p.55-66, 2017.

OWUSU-FORDJOUR, C; KOOMSON, C. K; HANSON, D. The impact of covid-19 on learning the perspective of the ghanaian student. European Journal of Education Studies, v. 7, Issue 03, p. 88-101, 2020.

PATHAK, Pallavi; GOPE, Tapan; BADER, Nadine. Effect of COVID-19 on public distribution system in India. International Journal of Community Medicine and Public Health. v.7, n.6, p. 2411- 2415, 2020.

PEDROSO, Maria Thereza Macedo; CORCIOLI, Graciella; FOGUESATTO, Cristian. A crise do Coronavírus e o agricultor familiar produtor de hortaliças. Gestão e Sociedade, v. 14, n. 39, p. 3740-3749, 2020.

POCHMANN, Marcio. Juventude em Busca de novos Caminhos no Brasil. In: NOVAES, Regina; VANNUCHI, Paulo (Organizadores). Juventude e Sociedade: trabalho, educação, cultura e participação social. São Paulo, Editora Fundação Perseu Abramo, p. 217-241, 2004.

REIS, Ana Carla Bittencourt. et al. Brazilian school feeding during the COVID-19 pandemic. SciELo Preprints, 2020. DOI: https://doi.org/10.1590/SciELOPreprints.791 . Disponível em: https://preprints.scielo.org/index.php/scielo/preprint/view/791. Acesso em: 02 set. 2020. 
RAITZ, Tânia Regina and PETTERS, Luciane Carmem Figueredo. Novos desafios dos jovens na atualidade: trabalho, educação e família. Psicol. Soc. [online]. v.20, n.3, p.408- 416, 2008.

ROCHA, Sonia. A inserção dos jovens no mercado de trabalho. Cad. CRH [online]. v. 21, n. 54, p.533-550, 2008.

SAMBUICHI, Regina Helena Rosa. et al. O Programa de Aquisição de Alimentos (PAA) como Estratégia de Enfrentamento aos desafios da COVID-19. Revista de Administração Pública, Rio de Janeiro, v. 54, n. 4, p. 1079-1096, 2020.

SILVA, Mauro Santos. Política econômica emergencial orientada para a redução dos impactos da pandemia da covid-19 no brasil: medidas fiscais, de provisão de liquidez e de liberação de capital. Brasília: Instituto de Pesquisa Econômica Aplicada, julho de 2020.

TOMMASI, Livia; CORROCHANO, Maria Carla. Do qualificar ao empreender: políticas de trabalho para jovens no Brasil. Estudos Avançados, № 34 (99), p. 353-371, 2020. DOI: 10.1590/s0103-4014.2020.3499.021 